\title{
GAMBARAN PENGETAHUAN IBU TENTANG PEMBERIAN IMUNISASI DASAR LENGKAP PADA BAYI DI PUSKESMAS KAMPUNG SAWAH KOTA TANGERANG SELATAN
}

\author{
* Ida listiana, ** Popon Retno Wulandari \\ Program Studi D3 Kebidanan, STIKes Widya Dharma Husada Tangerang \\ Jalan Pajajaran No1, Pamulang Tangerang Selatan Banten \\ idalistiana@wdh.ac.id
}

\begin{abstract}
ABSTRAK
Tujuan : Penelitian ini bertujuan mengetahui gambaran pengetahuan ibu tentang pemberian imunisasi dasar lengkap pada bayi di Puskesmas Kampung Sawah Tangerang Selatan Tahun 2016. Metode : Penelitian ini menggunakan metode deskriptif berdasarkan umur ibu, tingkat pendidikan, pekerjaan dan sumber informasi. Sampel penelitian diambil dengan teknik Non Probability Sampling secara Purposive Sampling. Jenis data yang digunakan dalam penelitian ini adalah data primer berupa kuesioner. Hasil : Hasil distibusi frekuensi gambaran pengetahuan ibu tentang pemberian imunisasi dasar lengkap pada bayi dapat diketahui bahwa dari 40 responden hampir setengahnya mempunyai pengetahuan cukup tentang pemberian imunisasi dasar lengkap pada bayi yaitu sebanyak 19 responden $(47,5 \%)$, dalam kategori umur ibu sebagian besar memiliki umur 20-35 tahun sebanyak 34 responden $(85 \%)$, dalam kategori pendidikan ibu dengan pendidikan lebih dari setengahnya memiliki tingkat pendidikan tinggi $(\leq$ SMA) sebanyak 26 responden $(65 \%)$, dalam kategori pekerjaan pada ibu lebih dari setengahnya adalah tidak bekerja sebanyak 24 responden (60\%), dalam kategori sumber informasi lebih dari setengahnya mendapatkan sumber informasi dari nakes sebanyak 24 responden $(60 \%)$. Diskusi : Dari hasil penelitian yang dilakukan bahwa pengetahuan ibu yang mengimunisasi bayinya yang berkunjung di PKM Kp.Sawah mayoritas memiliki pengetahuan cukup. Kesimpulan : Dengan adanya penelitian ini maka perlu adanya sosialisasi mengenai Imunisasi Dasar Lengkap dengan Tujuan untuk meningkatkan pengetahuan dan Setatus kelengkapan imunisasi dasar pada bayi.
\end{abstract}

Kata Kunci : Imunisasi Dasar, Pengetahuan

\begin{abstract}
Objective: This study aimed to picture mother's knowledge regarding the provision of complete basic immunization in infants at Puskesmas Kampung Sawah South Tangerang Year 2016. Methods: This study used a descriptive method based on maternal age, education level, employment and resources. Samples were taken by the Non-Probability Sampling technique is purposive sampling. The data used in this research is the primary data in the form of a questionnaire. Results: The frequency distibusi picture mother's knowledge regarding the provision of complete basic immunization in infants can be seen that nearly half of the 40 respondents have enough knowledge about the complete basic immunization in infants as many as 19 respondents (47.5\%), in the category of most of the mother's age have a lifespan of 20-35 years as many as 34 respondents (85\%), in the category of mother's education with education more than half had a higher education level (SSMA) of 26 respondents (65\%), in the category of work in the mother more than half are not working as many as 24 respondents (60\%), in the category of resources more than half of health workers get resources from as many as 24 respondents (60\%). Discussion: From the results of research conducted that knowledge of mothers to immunize their babies who visit the PKM Kp.Sawah majority have sufficient knowledge. Conclusion: With this study, it is necessary to complete the socialization of Primary Immunization with the goal of raising the knowledge and setatus completeness of basic immunization in infants.
\end{abstract}

Keywords: Immunization Basics, Knowledge 
PENDAHULUAN

Menurut WHO (World Health

Organazation) Imunisasi telah terbukti sebagai salah satu upaya kesehatan masyarakat yang sangat penting. Program imunisasi telah menunjukan keberhasilan yang luar biasa dan merupakan usaha yang sangat hemat biaya dalam mencegah penyakit menular. Sejak penetapan The Expended Program oleh WHO, cakupan imunisasi dasar anak dari $50 \%$ mendekati $80 \%$ diseluruh dunia. WHO telah merencanakan program ini (Global Proammer For Vaccines and Immunication) organisasi pemerintah di seluruh dunia bersama UNICEP, WHO dan World Bank (WHO, 2011 dalam Saragih,2011).

Pada tahun 1974, WHO merencanakan Expamded Proramme of Immunization (EPI) atau Program Pengembangan Imunisasi (PPI). Pengembangan pada program ini adalah penambahan penyakit target. Sebelum program ini berjalan. imunisasi yang dijalankan hanya berfokus pada penyakit smallpox, tuberkulosis, difteri, tetanus dan pertusis. Pada program ini terdapat 6 penyakit target yaitu difteri, tetanus, pertusis, polio, campak dan tuberculosis. Sementara imunisasi hepatitis B dimasukkan belakangan karena baru tersedia pada tahun 1980. Hasil dari program PPI meningkatkan angka cakupan imunisasi dari 5\% menjadi $80 \%$ pada tahun 1990 dan telah menyelamatkan lebih dari 20 juta jiwa anak dari penyakit infeksi (Gondowardojo, 2014).

Rata-rata angka imunisasi di Indonesia hanya $72 \%$. Ada sekitar 2.400 anak di indonesia meninggal setiap hari termasuk yang meninggal karena sebabsebab yang seharusnya dapat dicegah, misalnya tuberculosis (TBC), campak,pertusis,diferi dan tetanus (UNICEF, 2013). Tanpa imunisasi kirakira 3 dari 100 anak akan meninggal karena penyakit campak, sebanyak 2 dari 100 kelahiran anak akan meninggal karena batuk rejan. Satu dari 100 kelahiran anak akan meninggal karena penyakit tetanus. Dari setiap 200.000 anak, 1 akan menderita penyakit polio.

Program UCI (Universal child immunization) yang ditetapkan oleh Departemen Kesehatan (Depkes) RI secara nasional pada tahun 1990 telah berhasil dicapai dengan cakupan DPT , polio dan campak minimal $80 \%$ sebelum umur 1 tahun. Sedangkan cakupan untuk DTP, polio dan BCG minimal $90 \%$. Target UCI merupakan tujuan antara (intermediate goal) yang berarti cakupan imunisasi untuk BCG, DPT, polio, campak, dan hepatitis B harus mencapai $80 \%$ baik ditingkat nasional, provinsi, 
dan kabupaten bahkan setiap desa (Ishak, 2014).

Imunisasi merupakan suatu cara untuk meningkatkan kekebalan seseorang secara aktif terhadap suatu antigen, sehingga bila ia terpajan pada antigen serupa tidak terjadi penyakit. Indonesia masih mengalami banyak masalah kesehatan yang cukup serius terutama dalam bidang kesehatan ibu dan anak. Pembangunan kesehatan sebagai bagian dari pembangunan nasional dilaksanakan secara bertahap dan berkesinambungan, serta ditunjukan untuk meningkatkan kesejahteraan rakyat secara menyeluruh. Hasil Survey Demografi dan kesehatan indonesia (SDKI) 2007 menunjukkan Angka Kematin Balita (AKB) 34 per 1.000 kelahiran Hidup dan angka Kematian Bayi (AKB) 44 per 1.000 Kelahiran Hidup. Target pecapaian sasaran di tahun 2015 yaitu Angka Kematian Bayi (AKB) 23 per 1.000 Kelahiran Hidup dan Angka Kematian Balita (AKBA) 32 per 1.000 Kelahiran Hidup. ( Kementrian Kesehatan RI, 2015).

Pemberian imunisasi dasar lengkap berguna untuk memberi perlindungan menyeluruh terhadap penyakit-penyakit yang berbahaya. Dengan memberikan imunisasi dasar lengkap sesuai jadwal, tubuh bayi dirangsang untuk memiliki kekebalan sehingga tubuhnya mampu kekebalan melawan serangan penyakit berbahaya (Depkes RI, 2011).

Namun program ini masih mengalami hambatan, yaitu penolakan dari orang tua dengan anggapan yang salah yang berkembang di masyarakat tentang imunisai, tingkat pengetahuan yang rendah, dan kesadaran yang kurang terhadap imunisasi. Untuk menilai kelengkapan status imunisasi dasar lengkap bagi bayi dapat dilihat dari cakupan imunisasi. Imunisasi lengkap : BCG, DPT, minimal 3 kali, Hepatitis B minimal 3, campak 1 kali, Menurut cacatan Kartu Menuju Sehat ( KMS ) atau KIA. Persentase balita yang pernah mendapat imunisasi ( Lengkap ) tahun 2007 - 2010 menurut provinsi Banten. BCG 92,02, DPT 87,83, Polio 87,43, Campak 77,19, Hepatitis B 85,55. Persentase anak umur 12-23 bulan yang mendapatkan imunisasi dasar menurut Provinsi Banten Rikesdas 2010, Imunisasi dasar lengkap di provinsi Banten 30,6 \% dari 100\%, Imunisasi dasar tidak lengkap di provinsi Banten $57,6 \%$ dari $100 \%$. Sedangkan Imunisasi dasar tidak sama sekali Banten 11,8\% dari $100 \%$. Berdasarkan jenis imunisasi persentase tertinggi adalah $\mathrm{BCG}(88,6 \%)$ dan terendah adalah DPT-HB3 $(75,6 \%)$ (Provinsi Banten Rikesdas,2010). 
Menurut Survey Di Puskesmas Kampung Sawah tahun 2014, cakupan imunisasi BCG sebanyak 1380 bayi (106 \%) menurun dibandingkan tahun 2013 sebanyak 1434 bayi (108,5 \%), polio 3 sebanyak 1340 bayi (103\%) menurun dibandingkan tahun 2013 sebanyak 1393 bayi (107,6 \%), DPT3 sebanyak 1371 (105\%) menurun dibandingkan tahun 2013 sebanyak 1393 (10,7 \%), Campak sebesar 1403 bayi (108\%) menurun juga dibandingkan tahun 2013 sebanyak 1451 (112\%) (Profil Puskesmas Kampung Sawah, 2014).

Berdasarkan latar belakang, setiap ibu harus mengetahui, memahami manfaat dan jarak waktu pemberian imunisasi dasar lengkap ke pada bayinya, sehingga peneliti tertarik untuk melakukan penelitian tentang “ Gambaran Pengetahuan Ibu Tentang Pemberian Imunisasi Dasar Lengkap Pada Bayi Di Puskesmas Kampung Sawah Kota Tangerang Selatan Tahun 2016.

\section{METODE}

Jenis penelitian survei bersifat deskriptif kuantitatif. Populasinya adalah seluruh ibu yang memiliki anak imunisasi yang berkunjung untuk imunisasi dasar ke Puskesmas Kampung Sawah Kecamatan Ciputat Kota Tangerang Selatan Tahun 2016 berdasarkan kunjungan di Puskesmas bulan April dari tanggal 29 April - 12 Mei 2016 yang terdiri dari $66 \mathrm{ibu}$ yang mengimunisasi bayinya. Sehingga jumlah populasi dari penelitian ini adalah sebesar 66 ibu yang datang ke Puskesmas untuk melakukan imunisasi pada bayinya berdasarkan data kunjungan imunisasi di puskesmas.

Sampel Oleh karena populasi ibu seluruh ibu yang memiliki bayi imunisasi yang berkunjung untuk imunisasi di Puskesmas Kampung Sawah Kota Tangerang Selatan Tahun 2016 adalah 40 orang. Teknik Sampling Sampel penelitian diambil dengan teknik Non Probability Sampling secara Purposive Sampling. Tekhnik Pengumpulan Data : Jenis data yang digunakan dalam penelitian ini adalah data primer. Analisis Data : Analisa yang digunakan pada penelitian ini yaitu analisa univariat.

\section{HASIL}

Tabel 4.1. Distribusi Frekuensi Pengetahuan Ibu Tentang Pemberian Imunisasi Dasar Lengkap Pada Bayi Di Puskesmas Kampung Sawah Kota Tangerang Selatan Tahun 2016

\begin{tabular}{ccc}
\hline Pengetahuan & $\begin{array}{c}\text { Frekuensi } \\
(\text { F })\end{array}$ & \% \\
\hline Baik & 11 & $27,5 \%$ \\
\hline Cukup & 19 & $47,5 \%$ \\
\hline Kurang & 10 & $25 \%$ \\
\hline Jumlah & $\mathbf{4 0}$ & $\mathbf{1 0 0 \%}$ \\
\hline
\end{tabular}


Berdasarkan Tabel 4.1 dapat diketahui bahwa dari 40 responden hampir setengahnya mempunyai pengetahuan cukup tentang pemberian imunisasi dasar lengkap pada bayi yaitu sebanyak 19 responden $(47,5 \%)$.

Tabel 4.2 Distribusi Frekuensi Pengetahuan Ibu Tentang Pemberian Imunisasi Dasar Lengkap Pada Bayi Berdasarkan Umur Di Puskesmas Kampung Sawah Kota Tangerang Selatan Tahun 2016

\begin{tabular}{|c|c|c|c|c|c|c|c|c|}
\hline \multirow{3}{*}{$\begin{array}{c}\mathbf{U m u} \\
\mathbf{r}\end{array}$} & \multicolumn{6}{|c|}{ Pengetahuan } & \multirow{3}{*}{$\mathbf{N}$} & \multirow{3}{*}{$\%$} \\
\hline & \multicolumn{2}{|c|}{ Baik } & \multicolumn{2}{|c|}{ Cukup } & \multicolumn{2}{|c|}{ Kurang } & & \\
\hline & $\mathbf{F}$ & $\%$ & $\mathbf{F}$ & $\%$ & $\mathbf{F}$ & $\%$ & & \\
\hline $\begin{array}{c}<20 \\
\text { Tahu } \\
n\end{array}$ & 0 & 0 & 1 & $\begin{array}{l}33 \\
3\end{array}$ & 2 & $\begin{array}{c}66 \\
7\end{array}$ & 3 & $\begin{array}{l}7, \\
5\end{array}$ \\
\hline $\begin{array}{c}20-35 \\
\text { Tahu } \\
n\end{array}$ & 11 & $\begin{array}{l}32 \\
, 3\end{array}$ & 16 & $\begin{array}{l}47 \\
, 1\end{array}$ & 7 & $\begin{array}{c}20 \\
6\end{array}$ & 34 & 85 \\
\hline $\begin{array}{c}>35 \\
\text { Tahu } \\
n\end{array}$ & 0 & 0 & 2 & $\begin{array}{c}66 \\
, 7\end{array}$ & 1 & $\begin{array}{c}33 \\
3\end{array}$ & 3 & $\begin{array}{l}7, \\
5\end{array}$ \\
\hline $\mathbf{N}$ & 11 & $\begin{array}{l}27 \\
, 5\end{array}$ & 19 & $\begin{array}{l}47 \\
, 5\end{array}$ & $\begin{array}{l}1 \\
0\end{array}$ & 25 & 40 & $\begin{array}{c}10 \\
0\end{array}$ \\
\hline
\end{tabular}

Berdasarkan Tabel 4.2 dapat diketahui bahwa dari 40 responden dalam kategori umur sebagian besar adalah umur 20-35 tahun sebanyak 34 responden (85\%), dan yang memiliki pengetahuan cukup sebanyak 16 responden $(47,1 \%)$.
Tabel 4.3. Distribusi Frekuensi Pengetahuan Ibu Tentang Pemberian Imunisasi Dasar Lengkap Pada Bayi Berdasarkan Pendidikan Di Puskesmas Kampung Sawah Kota Tangerang Selatan Tahun 2016

\begin{tabular}{|c|c|c|c|c|c|c|c|c|}
\hline \multirow{3}{*}{$\begin{array}{l}\text { Pendid } \\
\text { ikan }\end{array}$} & \multicolumn{6}{|c|}{ Pengetahuan } & \multirow{3}{*}{$\mathbf{N}$} & \multirow{3}{*}{$\%$} \\
\hline & \multicolumn{2}{|c|}{ Baik } & \multicolumn{2}{|c|}{ Cukup } & \multicolumn{2}{|c|}{ Kurang } & & \\
\hline & $\mathbf{F}$ & $\%$ & $\mathbf{F}$ & $\%$ & $\mathbf{F}$ & $\%$ & & \\
\hline \multirow{2}{*}{$\geq \mathrm{SMA}$} & \multirow{2}{*}{9} & 34 & 1 & 61 & \multirow{2}{*}{1} & \multirow{2}{*}{3,8} & \multirow{2}{*}{26} & \multirow{2}{*}{65} \\
\hline & & ,6 & 6 & ,6 & & & & \\
\hline$(<$ SMA & \multirow{2}{*}{2} & 14 & \multirow{2}{*}{3} & 21 & \multirow{2}{*}{9} & 64, & \multirow{2}{*}{14} & \multirow{2}{*}{35} \\
\hline ) & &, 3 & & , & & 3 & & \\
\hline Jumla & 1 & 27 & 1 & 47 & 1 & \multirow{2}{*}{25} & \multirow{2}{*}{40} & 10 \\
\hline $\mathbf{h}$ & 1 &, 5 & 9 & 5, & $\mathbf{0}$ & & & $\mathbf{0}$ \\
\hline
\end{tabular}

Berdasarkan Tabel 4.3 dapat diketahui bahwa dari 40 responden dalam kategori pendidikan lebih dari setengahnya adalah tingkat pendidikan tinggi ( $\geq$ SMA) sebanyak 26 responden (65\%), yang memiliki pengetahuan cukup sebanyak 16 responden $(61,6 \%)$.

Tabel 4.4. Distribusi Frekuensi Pengetahuan Ibu Tentang Pemberian Imunisasi Dasar Lengkap Pada Bayi Berdasarkan Pekerjaan Di Puskesmas Kampung Sawah Kota Tangerang Selatan Tahun 2016

\begin{tabular}{|c|c|c|c|c|c|c|c|c|}
\hline \multirow{3}{*}{$\begin{array}{c}\text { Pekerj } \\
\text { aan }\end{array}$} & \multicolumn{6}{|c|}{ Pengetahuan } & \multirow{3}{*}{$\mathbf{N}$} & \multirow{3}{*}{$\%$} \\
\hline & \multicolumn{2}{|c|}{ Baik } & \multicolumn{2}{|c|}{$\begin{array}{c}\text { Cuku } \\
\mathbf{p}\end{array}$} & \multicolumn{2}{|c|}{ Kurang } & & \\
\hline & $\mathbf{F}$ & $\%$ & $\mathbf{F}$ & $\%$ & $\mathbf{F}$ & $\%$ & & \\
\hline $\begin{array}{c}\text { Bekerj } \\
\text { a }\end{array}$ & 8 & 50 & 8 & 50 & 0 & 0 & 16 & 40 \\
\hline $\begin{array}{c}\text { Tidak } \\
\text { Bekerj } \\
\text { a }\end{array}$ & 3 & $\begin{array}{r}12 \\
, 5\end{array}$ & $\begin{array}{l}1 \\
1\end{array}$ & $\begin{array}{r}45 \\
9\end{array}$ & 10 & $\begin{array}{r}41 \\
, 6\end{array}$ & 24 & 60 \\
\hline $\begin{array}{c}\text { Jumla } \\
\text { h }\end{array}$ & 11 & $\begin{array}{l}27 \\
, 5\end{array}$ & $\begin{array}{l}1 \\
9\end{array}$ & $\begin{array}{l}47 \\
, 5\end{array}$ & 10 & 25 & 40 & $\begin{array}{c}10 \\
0\end{array}$ \\
\hline
\end{tabular}

Berdasarkan Tabel 4.4 dapat diketahui bahwa 40 responden dalam kategori pekerjaan lebih dari setengahnya adalah 
tidak bekerja sebanyak 24 responden (60\%), yang memiliki pengetahuan cukup sebanyak 11 responden $(45,9 \%)$.

Tabel 4.5. Distribusi Frekuensi Pengetahuan Ibu Tentang Pemberian Imunisasi Dasar Lengkap Pada Bayi Berdasarkan Sumber Informasi Di Puskesmas Kampung Sawah Kota Tangerang Selatan Tahun 2016

\begin{tabular}{|c|c|c|c|c|c|c|c|c|}
\hline \multirow{3}{*}{$\begin{array}{c}\text { Sumb } \\
\text { er } \\
\text { Infor } \\
\text { masi }\end{array}$} & \multicolumn{6}{|c|}{ Pengetahuan } & \multirow{3}{*}{$\mathbf{N}$} & \multirow{3}{*}{$\%$} \\
\hline & \multicolumn{2}{|c|}{ Baik } & \multicolumn{2}{|c|}{ Cukup } & \multicolumn{2}{|c|}{ Kurang } & & \\
\hline & $\mathbf{F}$ & $\%$ & $\mathbf{F}$ & $\%$ & $\mathbf{F}$ & $\%$ & & \\
\hline \multirow{2}{*}{ Nakes } & \multirow{2}{*}{11} & 45 , & 1 & 45 & \multirow[t]{2}{*}{2} & 8, & \multirow{2}{*}{24} & \multirow{2}{*}{60} \\
\hline & & 8 & 1 & ,9 & & 3 & & \\
\hline $\begin{array}{c}\text { Non } \\
\text { Nakes }\end{array}$ & 0 & 0 & 8 & 50 & 8 & 50 & 16 & 40 \\
\hline \multirow{2}{*}{$\mathbf{N}$} & \multirow{2}{*}{11} & 27, & 1 & 47 & \multirow{2}{*}{10} & \multirow{2}{*}{25} & \multirow{2}{*}{40} & 10 \\
\hline & & 5 & 9 & 5, & & & & 0 \\
\hline
\end{tabular}

Berdasarkan Tabel 4.5 dapat diketahui bahwa dari 40 responden dalam kategori sumber informasi lebih dari setengahnya adalah nakes sebanyak 24 responden (60\%), yang memiliki pengetahuan cukup sebanyak 11 responden $(45,9 \%)$.

\section{PEMBAHASAN}

1. Variabel Dependen

a. Distribusi Frekuensi Pengetahuan Ibu Tentang Pemberian Imunisasi Dasar Lengkap Pada Bayi Di Puskesmas Kampung Sawah Kota Tangerang Selatan Tahun 2016.

Dari hasil penelitian terdapat 40 responden menunjukkan pengetahuan ibu tentang pemberian imunisasi dasar lengkap pada bayi di Puskesmas Kampung Sawah
Kota Tangerang Selatan tahun 2016 bahwa hampir setengahnya mempunyai pengetahuan cukup tentang pemberian imunisasi dasar lengkap pada bayi yaitu sebanyak 19 responden $(47,5 \%)$.

Hal ini dapat dikatakan bahwa mayoritas ibu memiliki tingkat pengetahuan terhadap pemberian imunisasi dasar cukup, dikarenakan mereka belum mendapatkan akses informasi kesehatan seperti penyuluhan, dan hal tersebut kemungkinan dipengaruhi oleh tingkat pendidikan yang kurang, informasi yang diperoleh dan sosial ekonomi.

Menurut Prasetyo dalam Gantini 2014, pengetahuan sesuatu yang ada dikepala kita. Kita dapat mengetahui sesuatu berdasarkan pengalaman yang kita miliki. Selain pengalaman, kita juga menjadi tau karen kita diberitahu oleh orang lain.

Menurut Mubarak tahun 2007 bahwa pendidikan berarti bimbingan yang diberikan seseorang pada orang lain terhadap suatu hal agar mereka dapat memahami tidak dapat dipungkiri bahwa makin tinggi pendidikan seseorang semakin mudah mereka menerima informasi dan pada akhirnya makin banyak pula pengetahuan yang dimilikinya. Dari hasil penelitian dan dasar teori dapat disimpulkan bahwa tingkat pengetahuan seseorang dapat ditentukan dengan jenjang 
pendidikan sehingga semakin tinggi pendidikan maka semakin tinggi pengetahuan. Oleh sebab itu diharapkan kepada responden agar dapat meningkatkan pengetahuannya dengan cara mencari informasi yang baik dan sebanyak mungkin tentang pemberian pemberian imunisasi dasar.

\section{Variabel Independen}

\section{a. Distribusi Frekuensi Pengetahuan Ibu}

Tentang Pemberian Imunisasi Dasar

Lengkap Pada Bayi Berdasarkan Usia

Di Puskesmas Kampung Sawah Kota

Tangerang Selatan Tahun 2016.

Dari hasil penelitian terdapat 40 responden menunjukkan pengetahuan ibu tentang pemberian imunisasi dasar lengkap pada bayi berdasarkan usia di Puskesmas Kampung Sawah Tangerang Selatan tahun 2016 bahwa dalam kategori umur sebagian besar yang memiliki pengetahuan cukup adalah 20-35 tahun sebanyak 34 responden $(85 \%)$.

Menurut Nusalam dan pariani tahun 2008, mendukung pada hasil penelitian bahwa semakin cukup umur, tingkat kematangan dan kekuatan seseorang akan lebih matang dalam berfikir dan bekerja.

Hal ini sesuai dengan hasil penelitian dan teori bahwa bertambahnya umur seseorang akan terjadi perubahan pada aspek fisik dan psikologis (mental). Pertumbuhan pada fisik secara garis besar ada empat kategori perubahan yaitu : perubahan ukuran, perubahan proporsi, hilangnya ciri-ciri lama, timbulnya ciri-ciri baru. Ini terjadi akibat pematangan fungsi organ, pada aspek psikilogis atau mental taraf berpikir semakin matang dan dewasa (Mubarak, 2007).

b. b. Distribusi Frekuensi Pengetahuan Ibu Tentang Pemberian Imunisasi Dasar Lengkap Pada Bayi Berdasarkan Pendidikan Di Puskesmas Kampung Sawah Kota Tangerang Selatan Tahun 2016.

Dari hasil penelitian terhadap 40 responden menunjukkan pengetahuan ibu tentang pemberian imunisasi dasar lengkap pada bayi bedasarkan pendidikan di Puskesmas Kampung Sawah Kota Tangerang Selatan tahun 2016 bahwa dalam kategori pendidikan lebih dari setengahnya adalah tingkat pendidikan tinggi ( $\geq \mathrm{SMA}$ ) sebanyak 26 responden $(65 \%)$.

Menurut Notoatmodjo tahun 2010, pendidikan seseorang dapat meningkatkan kematangan intelektualnya, sehingga dapat membuat keputusan dalam bertindak. Seseorang yang memiliki latar belakang yang tinggi (formal) akan mempunyai tingkat penalaran pengetahuan yang tinggi dan mempunyai presepsi bermacammacam tentang sesuatu hal dibandingkan dengan orang yang berpendidikan rendah. 
Hal ini sesuai dengan teori bahwa pendidikan seseorang dapat meningkatkan kematangan intelektualnya, sehingga dapat membuat keputusan dalam bertindak. Seseorang yang memiliki latar belakang yang tinggi (formal) akan mempunyai tingkat penalaran pengetahuan yang tinggi dan mempunyai presepsi bermacammacam tentang sesuatu hal dibandingkan dengan orang yang berpendidikan rendah menurut (Mubarok, 2007).

\section{c.Distribusi Frekuensi Pengetahuan Ibu} Tentang Pemberian Imunisasi Dasar Lengkap Pada Bayi Berdasarkan Pekerjaan Di Puskesmas Kampung Sawah Kota Tangerang Selatan Tahun 2016.

Dari hasil penelitian terhadap 40 reponden menunjukkan bahwa pengetahuan ibu tentang pemberian imunisasi dasar lengkap pada bayi berdasarkan pekerjaan di Puskesmas Kampung Sawah Tangerang Selatan tahun 2016 bahwa dalam kategori pekerjaan lebih dari setengahnya adalah tidak bekerja sebanyak 24 responden (60\%),

Hal ini menunjukan bahwa penelitian ini tidak sesuai dengan penelitian dan teori yang ada dengan pendapat Erfandi tahun (2011), Pekerjaan dapat menjadikan seseorang memperoleh pengalaman dan pengetahuan baik secara langsung maupun secara tidak langsung. maka peneliti berpendapat bahwa karena ibu yang tidak bekerja lebih banyak meluangkan waktu sehingga ibu bisa mencari informasi mulai dari ponsel, Televisi bahkan penyuluhan yang diadakan di posyandu setempat, dan ibu yang bekerja diluar rumah tidak bisa meluangkan waktu mereka untuk mendapatkan informasi mengenai kesehatan.

B. d.Distribusi Frekuensi Pengetahuan Ibu Tentang Pemberian Imunisasi Dasar Lengkap Pada Bayi Berdasarkan Sumber Informasi Di Puskesmas Kampung Sawah Kota Tangerang Selatan Tahun 2016.

Dari hasil penelitian terdapat 40 responden menunjukan pengetahuan ibu tentang pemberian imunisasi dasar lengkap berdasrakan sumber informasi di Puskesmas Kampung Sawah Kota Tangerang Selatan tahun 2016 bahwa responden dalam kategori sumber informasi lebih dari setengahnya adalah nakes sebanyak 24 responden (60\%).

Maka akan dikatakan bahwa pada penelitian ini mayoritas responden yang memiliki tingkat pengetahun tinggi yaitu didapat dari nakes (tenaga kesehatan) hanya sebagian kecil yang mengetahui informasi tentang pemberian imunisasi dasar lengkap dari non nakes (media masa, media elektonik, media cetak) 
Menurut Mubarak tahun 2007,

Kemudahan untuk memperoleh suatu

informasi dapat membantu mempercepat

seseorang untuk memperoleh pengetahuan yang baru. Dengan banyak informasi yang diperoleh, maka semakin bertambah pula pengetahuan seseorang (Depkes RI, 2009).

Hal ini sesuai dengan teori bahwa informasi yang diperoleh baik dari pendidikan formal maupun non formal dapat memberikan pengaruh jangka pendek (immediate impact) sehingga menghasilkan perubahan atau peningkatan pengetahuan. Majunya teknologi akan tersedia bermacam-macam media massa yang dapat mempengaruhi pengetahuan masyarakat tentang inovasi baru. Sebagai sarana komunikasi, berbagai bentuk media massa seperti televisi, radio, surat kabar, majalah, dan lain-lain (Non nakes) serta pemberian informasi oleh tenaga kesehatan (Nakes).

\section{KESIMPULAN}

1. Pengetahuan ibu tentang pemberian imunisasi dasar lengkap pada bayi di Puskesmas Kampung Sawah Kota Tangerang Selatan Tahun 2016 adalah dapat diketahui bahwa hampir setengahnya responden mempunyai pengetahuan cukup tentang pemberian imunisasi lengkap pada bayi yaitu 19 responden $(47,5 \%)$.
2. Pengetahuan ibu tentang pemberian imunisasi dasar lengkap pada bayi berdasarkan Umur di Puskesmas Kampung Sawah Kota Tangerang Selatan tahun 2016 sebagian besar memiliki umur 20-35 tahun sebanyak 34 responden $(85 \%)$.

3. Pengetahuan ibu tentang pemberian imunisasi dasar lengkap pada bayi berdasarkan Pendidikan di Puskesmas Kampung Sawah Kota Tangerang Selatan tahun 2016 ibu lebih dari setengahnya memiliki tingkat pendidikan tinggi $(\leq$ SMA) sebanyak 26 responden $(65 \%)$.

4. Pengetahuan ibu tentang pemberian imunisasi dasar lengkap pada bayi berdasarkan Pekerjaan di Puskesmas Kampung Sawah Kota Tangerang Selatan tahun 2016 lebih dari setengahnya adalah tidak bekerja sebanyak 24 responden (60\%).

5. Pengetahuan ibu tentang pemberian imunisasi dasar lengkap pada bayi berdasarkan Sumber Informasi di Puskesmas Kampung Sawah Kota Tangerang Selatan tahun 2016 lebih dari setengahnya mendapatkan sumber informasi dari nakes sebanyak 24 responden $(60 \%)$.

\section{DAFTAR PUSTAKA}


2010. Metode Penelitian

Kesehatan . Jakarta: Rineka Cipta.

Arikunto S. 2010. Prosedur Penelitian Suatu Pendekatan Praktik. Jakarta: PT.Rhineka Cipta

Anik Maryuni. 2010. Ilmu Kesehatan Anak Dalam Kebidanan “ Jakarta :Trans Info Medika.

Departemen Kesehatan Republik Indonesia. 2009. Cara Pemberian Imunisasi. Jakarta : Depkes.

Gandowardjo,Yustius Robby Budiman, dkk. 2016. Tingkat pengetahuan,sikap,dan perilaku ibu mengenai imunisasi dasar pada bayi di wilayah kerja puskesmas bebandem tahun 2014. FKUNUD.ojs.unud.ac.id/index.ph p/eum/article/download/13058/873 9 (Diakses Tanggal 18 Mei 2016 Pukul 19.35 Wib)

Hidayat, A dan Aziz almul. 2011. Ilmu Kesehatan Anak Untuk Pendidikan Kebidanan. Jakarta: Salemba Medika.

Kementrian Kesehatan RI. 2015. Rencana Strategis Kementrian Kesehatan Tahun 2015-2019. http://www.depkes.go.id/resources /download/info-publik/Rensta2015.pdf. (Diakses Tanggal 23 Mei pukul 20.00 Wib)

Mubarak, Wahit Iqbal. 2007. Ilmu Keperawatan Komunitas Konsep dan Aplikasi. Jakarta : Salemba Medika

Muslihatun, Wafi Nur. 2010. Asuhan Nenoatus,Bayi dan Balita Yogyakarta: Fitramaya.
Nanny Lia Dewi,Vivian. 2010. Asuhan Nenonatus Bayi dan Anak Balita .Jakarta: Salemba Medika.

Notoadmodjo, S. 2010. Ilmu Perilaku Kesehatan. Jakarta: Rineka Cipta, 2010.

Nur Anisa Noviana. Jejang Pendidikan Formal Di Indonesia Menurut Undang-Undang Sistem Pendidikan Nasional Tahun 2014..http://ilmu pendidik.net/pendidik/peraturan/je njang-pendidikan-formal-diindonesia-uu susdiknas-2003. (Diakses tanggal 23 Mei pukul 22.39 Wib)

Punaji Setyosari. 2010. Metode Penelitian Pendidikan dan Pengembangan. Jakarta: Kencana.

Ranuh, dkk. 2011. Pedoman Imunisasi di Indonesia. Jakarta: Badan Penerbit IDAI.

Riyanto, A. 2011. Aplikasi Metodologi Penelitian Kesehatan. Yogyakarta: Nuha Medika

Saragih, Rosita. 2016. Tingkat Pengetahuan Ibu Tentang Pemberian Imunisasi Dasar Pada Bayi Di Puskesmas Polonia Tahun 2011. Universitas Darma Agung,Medan.http://www.uda.ac.i d/jurnal/files/Rosita\%20Saragih3. (Diakses Tanggal 10 Mei 2016 Pukul 19.37 Wib)

Swarjana, I Ketuk. 2013. Metode Penelitian Kesehatan. Yogyakarta: Andi.

Sugiono, dkk. 2010. Stastika Untuk Penelitian" Bandung: Alpabeta. 